\title{
Interaction between angiotensin II and relaxin 2 in the progress of growth and spread of prostate cancer cells
}

\author{
KAMILA DOMIŃSKA ${ }^{1}$, TOMASZ OCHĘDALSKI ${ }^{1}$, KAROLINA KOWALSKA ${ }^{1}$, ZUZANNA ELŻBIETA \\ MATYSIAK-BURZYŃSKA ${ }^{1}$, ELŻBIETA PŁUCIENNIK ${ }^{2}$ and AGNIESZKA WANDA PIASTOWSKA-CIESIELSKA ${ }^{1}$
}

Departments of ${ }^{1}$ Comparative Endocrinology, ${ }^{2}$ Molecular Cancerogenesis, Medical University of Lodz, 90-752 Lodz, Poland

Received January 18, 2016; Accepted February 18, 2016

DOI: 10.3892/ijo.2016.3458

\begin{abstract}
Deregulation of locally secreted hormones, such as angiotensin II (Ang II) and relaxin 2 (RLN2), has been linked to a higher risk of select cancers or a poor prognosis in patients. In this study, for the first time a common effect of Ang II and RLN2 in relation to various aspects of prostate cancer development and metastasis are presented. Four independent colorimetric assays were used to analyze cell viability and proliferation. The changes of cell adhesion to extracellular matrix proteins and invasion/aggressiveness ability of prostate cancer cells ( $\mathrm{LNCaP}, \mathrm{PC} 3$ ) before and after peptides treatment, were also investigated. The findings suggest that the both investigated systems, have an impact on cell growth/division or spread, to some degree via overlapping signal transduction pathways. Intermediate or sometimes poorer results were achieved by using a combination of both hormones than when each was used individually. It seems that Ang II and RLN2 can play a significant role in increasing the aggressiveness of prostate tumors by up-regulating BIRC5 expression and MMP-2 and MMP-9 secretion. In addition, we speculate that Ang II and RLN2 are involved in the transition from the androgen-dependent to the androgen-independent phenotype via modulation of the expression of androgen receptors.
\end{abstract}

\section{Introduction}

It is common knowledge that not only steroid sex hormones are implicated in the development and progression of cancer of reproductive and non-reproductive tissues. Deregulation of certain peptide hormones, such as angiotensin and relaxin, has been linked to a higher risk of certain cancers or a poor prognosis in patients (1-3). Changes in selected components of the renin-angiotensin system (RAS) and relaxin family

Correspondence to: Dr Kamila Domińska, Department of Comparative Endocrinology, Medical University of Lodz, ul. Zeligowskiego 7/9, 90-752 Lodz, Poland

E-mail:kamila.dominska@umed.lodz.pl

Key words: angiotensin II, relaxin 2, prostate cancer, androgen receptor, matrix metalloproteinases 2, -9, BIRC5, BCL2, BAX peptide system have been observed in pathological states of the prostate, including the chronic inflammatory state, prostatic hyperplasia $(\mathrm{BPH})$ or prostate cancer (PC). It has been shown that these peptides are able to modulate cell proliferation and apoptosis, invasion and spread of many types of cells. High expression of relaxin 2 and the relaxin receptor LGR7/RXFP1 as well as angiotensin II and angiotensin receptor type 1 (AT1) was observed in tumor tissue compared to normal prostate tissue. Studies suggest that both the expression of the LGR7/ RXFP1 and AT1 receptors can be new early markers of metastatic potential in primary tumors (4-8).

Interactions between RAS and the relaxin family peptide system have been reported in organ fibrosis (9), blood pressure, in the cardiovascular system $(10,11)$, and osmoregulation, for the central nervous system $(12,13)$ but so far, never in the carcinogenesis of reproductive tissues. However, this study is the first to present the influence of the combined action of angiotensin II and relaxin 2 on various aspects of prostate cancer development and progression.

The effects of these peptide hormones, alone and in combination, were investigated on cell viability and proliferation in both two-dimensional (2D) and three-dimensional (3D) Geltrex $^{\mathrm{TM}}$ cultures. The 3D culture system allows complex interactions to take place between normal cell-cell and cellextracellular matrices which are not possible under monolayer growth conditions (14). Survival pathway analysis included the expression of the anti-apoptotic genes BCL2, survivin and pro-apoptotic $B A X$. Studies indicate that survivin (BIRC5), an inhibitor of apoptosis, mediates resistance to anti-androgen therapy in prostate cancer (15). High levels of BIRC5 mRNA expression and decreased $B A X$ to $B C L 2$ ratio are predictors of poor prognosis in many cancer types. These results suggest that $B I R C 5$ expression or the $B C L 2 / B A X$ expression ratio may be a potential molecular marker for the progression and aggressiveness of prostate cancer (15-17).

Adhesion plays an important role in both the migration and invasion of cancer cells (14). Therefore, we examined the influence of the peptides on the ability of prostate cancer cells to proliferate without adhering to the substratum, as well as their ability to adhere to extracellular matrix (ECM) proteins. The potential relationship between angiotensin II and relaxin 2 regarding the secretion levels of metalloproteinases- 2 and metalloproteinase- 9 was also assessed. The action of matrix metalloproteinases (MMPs), enzymes which mediate the 
degradation of basement membrane proteins, was found to strictly correlate with the invasion and metastasis of various malignancies. Significantly higher plasma levels of MMP-2 and MMP-9 were diagnosed in patients with metastatic prostate cancer than patients with organ-confined carcinomas and healthy controls (18).

\section{Materials and methods}

Cell lines and 2D/3D culture conditions. LNCaP (American Type Culture Collection; CRL-1435), is a hormone-dependent line with high androgen receptor (AR) activity. The cells of the LNCaP line are characterised by relatively slow growth and low invasiveness. PC3 cells (American Type Culture Collection; CRL-1740) display high metastatic potential and low AR expression (19). Cell lines were authenticated by shorttandem repeat (STR) DNA profiling (LGC Standards Cell Line Authentication Service, Germany). The cells were grown in two-dimensional (2D) cell cultures or three-dimensional (3D) basement membrane cultures. The cells were seeded in plates or flasks (BD Biosciences) and were maintained in Advanced RPMI-1640 supplemented with 5\% fetal bovine serum (FBS), 2 mM L-glutamine, $1 \mathrm{mM}$ sodium pyruvate and antibiotics. For 3D culture, plates were coated with Geltrex LDEV-FreeBasement Membrane Matrix, according to the manufactures instructions Gibco ${ }^{\circledR}$ (Thermo Fisher Scientific, Inc.). Moreover, the culture medium additionally contained $2 \%$ Geltrex. Both cell lines were incubated at $37^{\circ} \mathrm{C}$, with $5 \%$ carbon dioxide. The cells were passaged at least twice after thawing from liquid nitrogen. For further experiments, cells passaged between 9 and 18 times were used.

Reagents. Angiotensin II (H-1705) and relaxin 2 (H-6784) were obtained from Bachem. The peptides were used at a final concentration of $10^{-8} \mathrm{M}$ for all experiments. This concentration was selected on the basis of earlier research work and trial experiments (6). The medium, FBS and other culture supplements / reagents were purchased from Gibco (Thermo Fisher Scientific, Inc.) unless otherwise specified.

Two-dimensional (2D) MTT and Alamar blue assay. The cells were seeded in a 96-well flat bottom plate and were maintained overnight in complete medium at $37^{\circ} \mathrm{C}$ and $5 \% \mathrm{CO}_{2}$. The cells were then incubated for $48 \mathrm{~h}$ with RLN2, Ang II alone or with a combination of both. Four hours prior to the end of the incubation period, $5 \mathrm{mg} / \mathrm{ml}$ MTT solution was diluted to a final concentration of $0.5 \mathrm{mg} / \mathrm{ml}$ and added to each well; this would clarify the difference in the concentrations. The formazan crystals formed by viable cells were dissolved in DMSO $(100 \mu \mathrm{l})$ and measured using a microplate reader $\left(\right.$ BioTek $\left.^{\circledR}\right)$ at $570 \mathrm{~nm}$. Alamar Blue ${ }^{\circledR}$ (Molecular Probes ${ }^{\circledR}$, Thermo Fisher Scientific, Inc.) was added to each well and was incubated for $1 \mathrm{~h}$. During incubation, the color of Alamar blue changed from blue to red. Absorbance was monitored at 570 and $600 \mathrm{~nm}$. The cell viability (\%) was calculated relative to control cells cultured in complete growth medium without RLN2 and Ang II.

Three-dimensional (3D) WST-1 assay. LNCaP and PC3 cells were cultured in a 3D environment. Following a 5-day 3D culture, the medium was removed and fresh medium, along with peptide hormones (Ang II, RLN2 or Ang II + RLN2) were added to the cultures. After $48 \mathrm{~h}$ of incubation, WST-1 was added to each well and incubated for another 1-2 h. A colorimetric indicator changed color from red to yellow depending on the number and metabolic activity of live cells. The colored reduction product was quantified using a microplate reader (BioTek) at $450 \mathrm{~nm}$. The effect of peptide hormones on cell viability was calculated as a percentage of the metabolic activity measured in the non-treated cells.

BrdUrd proliferation assay. Detailed procedures for the colorimetric BrdUrd proliferation assay (Roche Diagnostics; 11647229001) have been previously described (20). The cells were seeded in a 96-well flat bottom plate and were maintained overnight in complete medium at $37^{\circ} \mathrm{C}$ and $5 \% \mathrm{CO}_{2}$. Then cells were treated with indicated concentration of Ang II and/ or RLN2 for $48 \mathrm{~h}$. Bromodeoxyuridine (BrdUrd) was added to the culture medium in the last $4 \mathrm{~h}$ of incubation. Absorbance was measured using a microplate reader (BioTek) at $450 \mathrm{~nm}$. Cell proliferation (\% of control) was calculated in relation to untreated controls.

Adhesion assay. Cells were seeded in a 6-well plate, with or without peptide hormones at a final concentration of $10^{-8} \mathrm{M}$. The cells were then collected after 24 or $48 \mathrm{~h}$ of incubation time. The populations of cells that detached from the substrate were added at concentrations of $1 \times 10^{5}$ cells/well to ECM-coated wells in RPMI/FBS-free medium, using 24-well tissue culture plates coated with human plasma fibronectin, laminin, collagen I or IV (BD Biosciences). After $90 \mathrm{~min}$ incubation at $37^{\circ} \mathrm{C}$ in a humidified atmosphere of $95 \%$ air $-5 \% \mathrm{CO}_{2}$, the cells were gently washed with PBS to remove non-adherent cells. Samples were fixed and stained with a $0.1 \%$ solution of crystal violet in $25 \%$ ethanol. Finally, cells were rinsed in water and solubilized by adding $10 \%$ acetic acid. The intensity of the violet color was measured by a microplate reader (BioTek) at $570 \mathrm{~nm}$. The data are presented as percentage relative to the untreated control.

Transwell invasion assay. In a similar way to the adhesion assay, the cells were seeded in a 6-well plate, with or without peptide hormones, and collected after 24-48 $\mathrm{h}$ of incubation time by typsinization. The cell suspension and standard medium, or experimental medium with peptides, were mixed at a final concentration $1 \times 10^{6}$ cells $/ \mathrm{ml}$, and added to the upper chambers. The undersides of the filters were made of $8 \mu \mathrm{m}$ pores which were coated with Matrigel (BD Biosciences). The lower chamber contained standard medium with $10 \%$ FBS. The cells were incubated for $48 \mathrm{~h}$ at $37^{\circ} \mathrm{C}$ with $5 \% \mathrm{CO}_{2}$. After this time, the incubated non-invading cells that remained on the upper surface of the filter were mechanically removed. Cells which migrated to the lower surface of the filter were fixed and stained with $1 \mathrm{mg} / \mathrm{ml}$ crystal violet solution prepared in $10 \%$ ethanol and then dissolved in $10 \%$ acetic acid. The cell invasion potential was quantified by measuring the absorbance at $570 \mathrm{~nm}$ (BioTek). The results are expressed as the percentage ratio over untreated, control cells.

Soft agar colony assay. The assay was performed in a 6 -well plate coated with $0.9 \%$ agar in growth medium. Cells 
Table I. Real-time RT-PCR primers and reaction conditions (22).

\begin{tabular}{llcc}
\hline Genes & \multicolumn{1}{c}{ Gene primers (5'-3') } & $\begin{array}{c}\text { Annealing } \\
\text { temp. }\end{array}$ & $\begin{array}{c}\text { Detection } \\
\text { temp. }\end{array}$ \\
\hline $\begin{array}{l}\text { H3F3A } \\
\text { (H3 histone, family 3A) }\end{array}$ & F: 5'-AGGACTTTAAAAGATCTGCGCTTCCAGAG-3' & $65^{\circ} \mathrm{C}$ & $72^{\circ} \mathrm{C}$ \\
RPLPO & R: 5'-ACCAGATAGGCCTCACTTGCCTCCTGC-3' & & $72^{\circ} \mathrm{C}$ \\
(Ribosomal phosphoprotein) & F: 5'-ACGGATTACACCTTCCCACTTGCTAAAAGGTC-3' & $65^{\circ} \mathrm{C}$ & \\
BAX & R: 5'-AGCCACAAAGGCAGATGGATCAGCCAAG-3' & & $81^{\circ} \mathrm{C}$ \\
& F: 5'-AGAGGTCTTTTTCCGAGTGGCAGC-3' & $56^{\circ} \mathrm{C}$ & \\
BCL2 & R: 5'-TTCTGATCAGTTCCGGCACCTTG-3' & & $81^{\circ} \mathrm{C}$ \\
BIRC5 & F: 5'-TTGGCCCCCGTTGCTTTTCCTC-3' & $56^{\circ} \mathrm{C}$ & $81^{\circ} \mathrm{C}$ \\
(Survivin) & R: 5'-TCCCACTCGTAGCCCCTCTGCGAC-3' & & \\
AR & F: 5'-AGTGTTTCTTCTGCTTCAAGGAGCTGGAAG-3' & $56^{\circ} \mathrm{C}$ & \\
(Androgen receptor) & R: 5'-ACCGGACGAATGCTTTTTATGTTCCTCTATG-3' & & $72^{\circ} \mathrm{C}$ \\
\hline
\end{tabular}

F, forward; R, reverse.

were prepared by trypsinization and suspended at a final concentration of $1 \times 10^{4}$ cells $/ \mathrm{ml}$ of $0.3 \%$ agarose in complete medium. The cells were then plated on the top of the agar and maintained at $37^{\circ} \mathrm{C}$ in a humidified incubator with $5 \% \mathrm{CO}_{2}$. Every 2-3 days, the cells were treated with another dose of the peptide hormones: Ang II, RLN2 or Ang II + RLN2. After 21 days, the colonies were stained with $0.05 \%$ crystal violet for at least $1 \mathrm{~h}$. The results were recorded and documented by scanning the plates. The number of colonies in each well were counted using ImageJ, a free image processing program from Wayne Rasband at the National Institutes of Health (http://imagej.nih.gov/ij).

Gelatin zymography assay. The matrix metalloproteinase activity (MMP-2 and MMP-9) in normal prostate epithelial cells, was determined by gelatin zymography, before and after peptide hormone treatment, as previously described (21). The prostate cancer cells were plated onto 6-well plates and incubated until $80 \%$ confluence, after which the medium was changed to fresh serum-free medium with or without peptide hormones at a concentration of $10^{-8} \mathrm{M}$. After $24 \mathrm{~h}$ of incubation, the conditioned culture medium was collected and stored at $-80^{\circ} \mathrm{C}$. The protein concentration was measured by Qubit ${ }^{\circledR}$ Protein Assay kit (Invitrogen ${ }^{\mathrm{TM}}$ Thermo Fisher Scientific, Inc.). Protein extracts (5-10 $\mu \mathrm{g})$ were subjected to electrophoresis in a $10 \%$ polyacrylamide gel in the presence of $4 \%$ gelatin. After the electrophoresis runs, the gels were washed for $1.5 \mathrm{~h}$ in $2.5 \%$ Triton $\mathrm{X}-100$ at room temperature. The gels were then incubated overnight at $37^{\circ} \mathrm{C}$ in the reaction buffer and sequentially stained with Coomassie brilliant blue and destained in a solution of $10 \%$ acetic acid and $30 \%$ methanol. Areas of enzymatic activity appeared as clear bands over a dark background. The density of gel bands was analyzed using ImageJ software.
Real-time RT-PCR. The prostate cancer cells were exposed to peptide hormones (Ang II, RLN2 and Ang II + RLN2) at a concentration of $1 \times 10^{-8} \mathrm{M}$, for $24 \mathrm{~h}$. The total RNA from cells was then extracted using a Universal kit (A\&A Biotechnology). The quantity of recovered RNA and its purity was determined by reading the absorbance at 260 and $280 \mathrm{~nm}$. Reverse transcriptase was used to create cDNA libraries from mRNA. Amplification reactions were performed with a LightCycler 480 Real-time PCR. The expression levels of investigated genes were normalized to two reference genes (H3F3A and RPLPO). All quantitative PCR data were analyzed using the relative expression software tool REST 2009 (version 2.0.13) which uses a hypothesis test to determine significant differences between control and sample groups. The software provides proper error propagation and robust statistical analysis by using a random reallocation algorithm with 2,000 iterations. The real-time RT-PCR primers and reaction conditions are presented in Table I (22).

Statistical analysis. The data are presented as mean \pm SD of at least three independent experiments. The measurements were subjected to analysis of variance (One-Way ANOVA) and Tukey's test using GraphPad Prism 5 (GraphPad Software, La Jolla, CA, www.graphpad.com). Relationships were regarded as statistically significant at $\mathrm{p}<0.05$.

\section{Results}

Effect of Ang II and/or RLN2 on cell viability and proliferation of prostate cancer cells. In 2D cultures (Fig. 1A), both peptides Ang II and RLN2 indeed improved the viability androgen-dependent prostate cancer cell lines. In androgen-independent prostate cancer cells, the results were unambiguous for example the Alamar blue assay showed a 


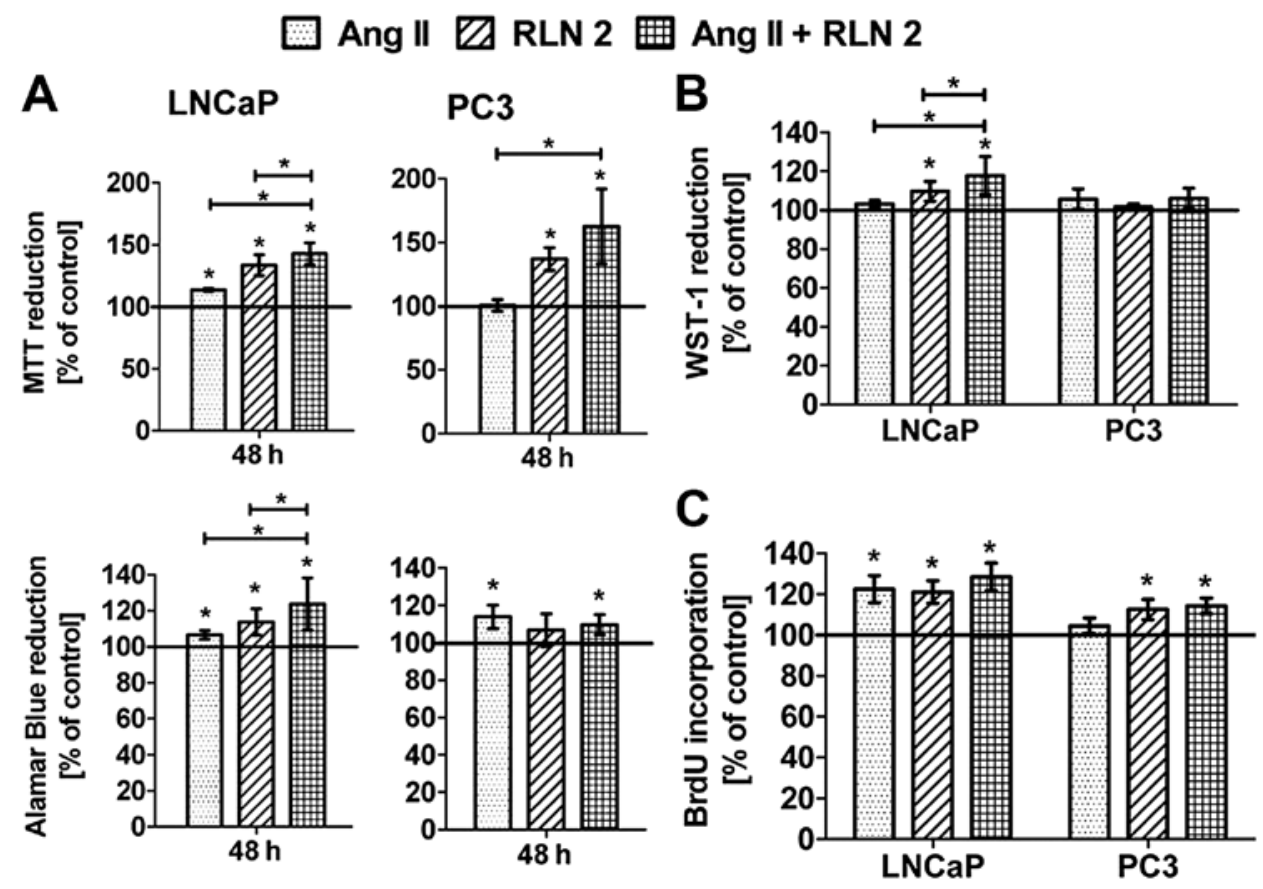

Figure 1. Cell viability and proliferation of prostate cancer lines after exposure to peptide hormones (Ang II, RLN2, Ang II + RLN2). (A) MTT and Alamar blue reduction assay data from a classical 2D cell culture system. (B) WST-1 reduction assay data from three-dimensional (3D) culture system. (C) BrdUrd incorporation assay data. (mean $\pm \mathrm{SD} ; \mathrm{n} \geq 5$; Tukey's test: " $\mathrm{p}<0.05$ ).

significant increase in PC3 cell viability after treatment with Ang II, the MTT method did not. The stimulating impact of the combination of peptide hormones on cell viability was more evident in LNCaP cells than PC3. Treatment of prostate cancer cells with both peptide hormones induced BrdU incorporation into DNA during the S-phase of the cell cycle (Fig. 1C). Ang II promoted cell division of LNCaP to a much greater degree than PC3, where the result was not statistically significant. In any case, no changes in cell proliferation were noted between Ang II and RLN2 used alone or a combination of both. The results of the 3D cultures (Fig. 1B) showed a similar trend to those of the 2D cell culture experiments (Alamar blue), although with less marked differences. Furthermore, the prostate cells were found to exhibit greater colony formation after 5-day treatment with Ang II and RLN2 (Fig. 2), especially after exposure to a combination of both peptide hormones.

Effect of Ang II and/or RLN2, on expression of AR, BCL2, $B A X, B I R C 5$ genes in prostate cancer cells. The results of the real-time reverse transcription PCR indicated that relative BIRC5 (survivin) expression to be more than 6 times higher in the PC3 cells than in LNCaP cells (data not shown). The results present increased levels of BIRC5 transcript in RNA extracts from prostate cancer cells treated with peptide hormones (Table II). However these results were statistically significant only in androgen-dependent cells. In both prostate cancer cell lines, expression of $B C L 2$ and $B A X$ was unchanged, the only exception being the LNCaP cells, which were incubated with RLN2 for $24 \mathrm{~h}$. In this case, a poor but significant increase was observed in the expression of the pro-apoptotic $B A X$ gene. The androgen receptor was expressed in both androgendependent and -independent prostate cancer lines. However, levels of $A R$ were found to be more than 30 times higher in LNCaP cells than PC3 cells (data not shown). The clear upward trend in androgen receptor expression was observed in androgen-dependent prostate cancer cells after exposure to Ang II and/or RLN2, this tendency was not noted in androgenindependent cells.

Effects of Ang II and/or RLN2 on adhesion of prostate cancer cells. The LNaP cells that were suspended in serumfree medium adhered efficiently to fibronectin, collagen I and IV, but not to laminin. Whereas the PC3 cells best adhered to fibronectin after $90 \mathrm{~min}$ of incubation, they adhered less effectively to both types of collagens and very weakly to laminin. In most cases, no differences were noted between the adhesion of the control cells and adhesion of the experimental group after 24-h incubation (date not shown). Prolongation of the incubation period to $48 \mathrm{~h}$ leads to increased cell adhesion in all tested variations (Fig. 3). In LNCaP cells, much more adhesion to collagen I and IV was observed after long-term treatment with Ang II and RLN2 alone than in combination. However, the adhesion of PC3 cells were frequently intermediate (collagens) or lower (fibronectin) after $48 \mathrm{~h}$ treatment with combined Ang II and RLN2 than the individual peptides.

Effects of Ang II and/or RLN2 on cell invasion of prostate cancer cells. Both LNCaP and PC3 cells have greater potential to invade through Matrigel-coated $8 \mu \mathrm{m}$ inserts in response to RLN2 and/or Ang II (Fig. 4A). However, it should be emphasized that this effect was observed only after longterm incubation. Relaxin 2 exerted the strong impact on the invasiveness of androgen-independent cell lines, whereas in androgen-dependent lines, the most notable was Ang II. In 


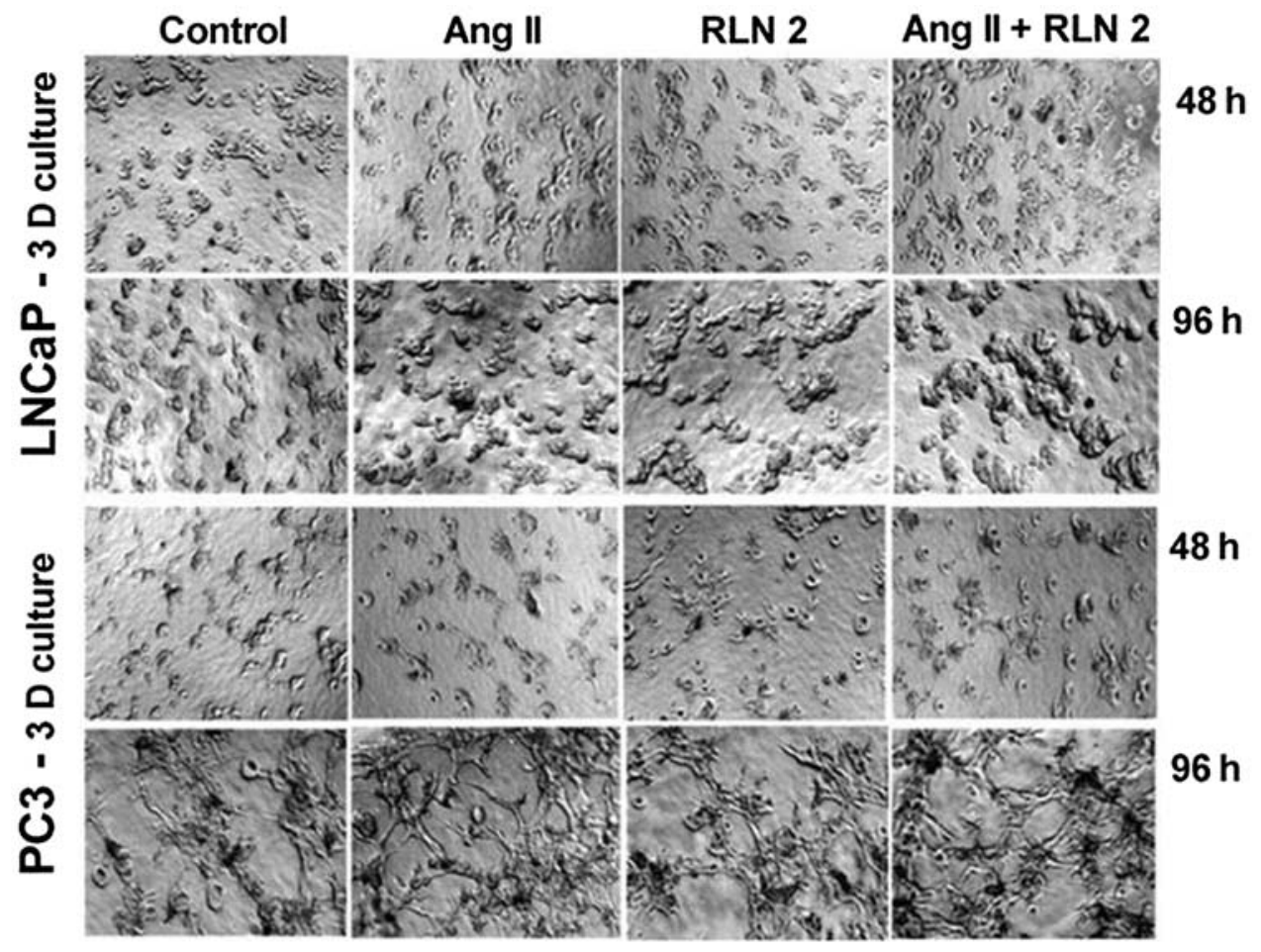

Figure 2. The colony formation of prostate cancer cells after exposure to peptide hormones (Ang II, RLN2, Ang II + RLN2) in three-dimensional (3D) culture systems. The panel shows representative pictures of the peptide hormone effect on size of 3D structures compared with control group. Prostate cancer cells grown on Geltrex for 1 day and then treated with peptides for another 5 days.

\section{LNCaP}

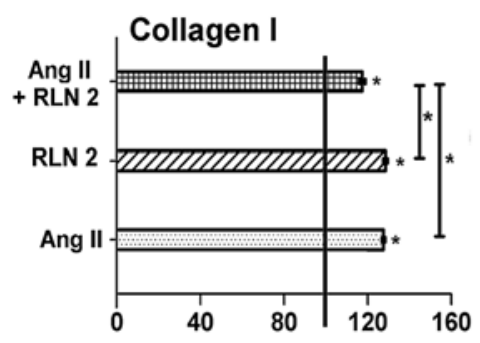

PC3

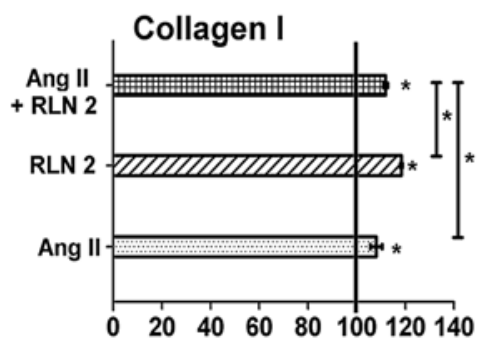

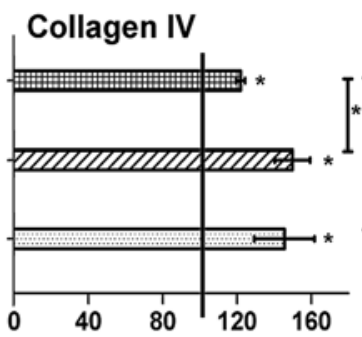

Cell adhesion [\% of control]
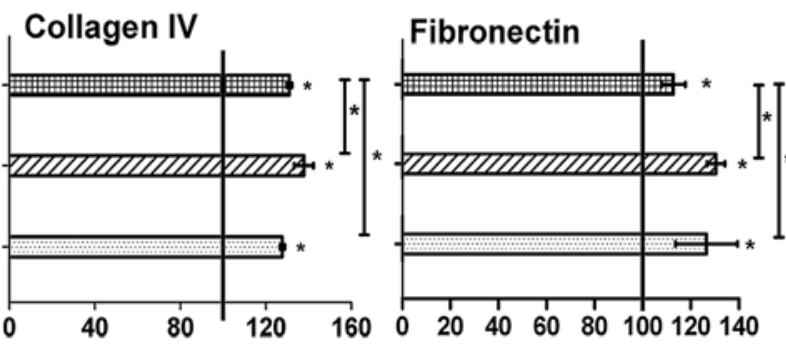

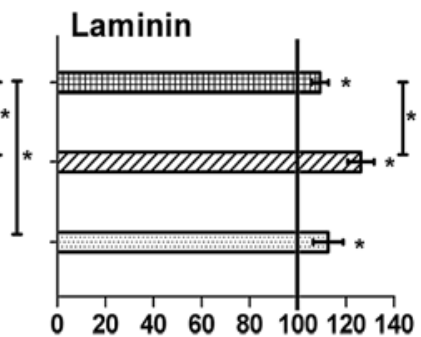

Cell adhesion [\% of control]

Figure 3. Adhesion of prostate cancer cells to extracellular matrix (ECM) proteins: laminin, fibronectin, collagen I and collagen IV after incubation (48 h) with Ang II and/or RLN2. Significant differences compared to controls are marked by asterisks (mean \pm SD; $n \geq 3$; Tukey's test: ${ }^{*} \mathrm{p}<0.05$ ).

both lines, the effect of combined RLN2 and Ang II was not significantly different than that of the individual effect of more powerful peptide hormone for this line.

Effect of Ang II and/or RLN2 on MMP-2 and MMP-9 secretion in prostate cancer cells. All of the samples contained two prominent gelatinolytic bands corresponding to monomeric pro-MMP-9 (92 kDa) and pro-MMP-2 (72 kDa) (Fig. 4B). Additionally, two slight complexes of MMPs (240 kDa and $130 \mathrm{kDa}$ ) were also observed in PC3 cells (data not shown). The levels of both MMPs significantly rose after exposure to peptide hormones, the only exception being the sample 
Table II. Expression of the genes $B C L 2, B A X, B I R C 5$ and $A R$ in prostate cancer cells after $24 \mathrm{~h}$ incubation with Ang II and/or RLN2.

LNCaP

\begin{tabular}{|c|c|c|c|c|c|c|c|c|}
\hline Treatment & Gene & Type & $\begin{array}{l}\text { Reaction } \\
\text { efficiency }\end{array}$ & Expression & Std. Error & $95 \% \mathrm{CI}$ & $\mathrm{P}(\mathrm{H} 1)$ & Result \\
\hline \multirow[t]{6}{*}{ Ang II } & H3F3A & REF & 0.92 & 1.261 & & & & \\
\hline & RPLPO & $\mathrm{REF}$ & 0.98 & 0.793 & & & & \\
\hline & $\mathrm{BCL}$ & TRG & 1.0 & 1.638 & $0.875-2.651$ & $0.651-4.639$ & 0.120 & $\leftrightarrow$ \\
\hline & BAX & TRG & 0.84 & 1.373 & $0.979-2.057$ & 0.904-2.499 & 0.086 & $\leftrightarrow$ \\
\hline & BIRC5 & TRG & 0.9 & 1.784 & $1.512-2.060$ & $1.335-2.289$ & 0.002 & $\uparrow$ \\
\hline & AR & TRG & 0.97 & 1.968 & $1.603-2.228$ & $1.420-2.718$ & 0.002 & $\uparrow$ \\
\hline \multirow[t]{6}{*}{ RLN2 } & H3F3A & $\mathrm{REF}$ & 0.92 & 1.592 & & & & \\
\hline & RPLPO & $\mathrm{REF}$ & 0.98 & 0.628 & & & & \\
\hline & BCL & TRG & 1.0 & 1.174 & $0.564-2.128$ & $0.416-3.665$ & 0.612 & $\leftrightarrow$ \\
\hline & BAX & TRG & 0.84 & 1.540 & $1.133-2.144$ & $0.926-2.881$ & 0.048 & $\uparrow$ \\
\hline & BIRC5 & TRG & 0.9 & 2.043 & $1.678-2.694$ & $1.355-2.902$ & 0.001 & $\uparrow$ \\
\hline & AR & TRG & 0.97 & 2.185 & $1.959-2.462$ & $1.752-2.936$ & 0.002 & $\uparrow$ \\
\hline \multirow[t]{6}{*}{ Ang II + RLN2 } & H3F3A & REF & 0.92 & 1.324 & & & & \\
\hline & RPLPO & REF & 0.975 & 0.755 & & & & \\
\hline & $\mathrm{BCL}$ & TRG & 1.0 & 0.986 & $0.682-1.532$ & $0.583-2.015$ & 0.950 & $\leftrightarrow$ \\
\hline & BAX & TRG & 0.84 & 1.240 & $0.789-1.878$ & $0.690-3.254$ & 0.385 & $\leftrightarrow$ \\
\hline & BIRC5 & TRG & 0.9 & 1.894 & $1.607-2.428$ & $1.308-2.503$ & 0.000 & $\leftrightarrow$ \\
\hline & AR & TRG & 0.97 & 1.319 & $1.045-1.687$ & $1.006-2.067$ & & $\leftrightarrow$ \\
\hline
\end{tabular}

PC3

\begin{tabular}{|c|c|c|c|c|c|c|c|c|}
\hline \multirow[t]{6}{*}{ Ang II } & H3F3A & REF & 0.92 & 1.236 & & & & \\
\hline & RPLPO & $\mathrm{REF}$ & 0.98 & 0.809 & & & & \\
\hline & BCL & TRG & 1.0 & 0.606 & $0.258-1.589$ & $0.136-3.029$ & 0.303 & $\leftrightarrow$ \\
\hline & BAX & TRG & 0.84 & 0.899 & $0.601-1.347$ & $0.444-2.108$ & 0.658 & $\leftrightarrow$ \\
\hline & BIRC5 & TRG & 0.9 & 1.064 & $0.661-1.588$ & $0.600-2.180$ & 0.783 & $\leftrightarrow$ \\
\hline & AR & TRG & 0.97 & 0.300 & $0.095-1.341$ & $0.027-2.002$ & 0.141 & $\leftrightarrow$ \\
\hline \multirow[t]{6}{*}{ RLN2 } & H3F3A & REF & 0.92 & 1.223 & & & & \\
\hline & RPLPO & REF & 0.98 & 0.818 & & & & \\
\hline & BCL & TRG & 1.0 & 0.527 & $0.198-1.389$ & $0.096-2.570$ & 0.196 & $\leftrightarrow$ \\
\hline & $\mathrm{BAX}$ & TRG & 0.84 & 0.798 & $0.487-1.263$ & $0.357-1.876$ & 0.327 & $\leftrightarrow$ \\
\hline & BIRC5 & TRG & 0.9 & 1.162 & $0.580-2.338$ & $0.373-3.297$ & 0.681 & $\leftrightarrow$ \\
\hline & $\mathrm{AR}$ & TRG & 0.97 & 0.269 & $0.072-0.967$ & $0.027-1.433$ & 0.107 & $\leftrightarrow$ \\
\hline \multirow[t]{6}{*}{ Ang II + RLN2 } & H3F3A & REF & 0.92 & 1.329 & & & & \\
\hline & RPLPO & REF & 0.98 & 0.753 & & & & \\
\hline & $\mathrm{BCL}$ & TRG & 1.0 & 0.659 & $0.278-1.603$ & $0.238-1.855$ & 0.360 & $\leftrightarrow$ \\
\hline & BAX & TRG & 0.84 & 0.818 & $0.464-1.310$ & $0.340-2.272$ & 0.479 & $\leftrightarrow$ \\
\hline & BIRC5 & TRG & 0.9 & 1.216 & $0.804-1.740$ & $0.640-2.490$ & 0.329 & $\leftrightarrow$ \\
\hline & AR & TRG & 0.97 & 0.354 & $0.076-0.927$ & $0.058-1.355$ & 0.158 & $\leftrightarrow$ \\
\hline
\end{tabular}

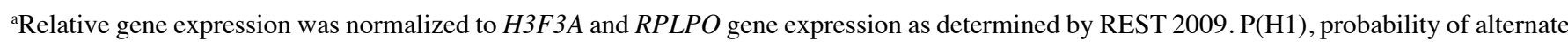
hypothesis that the difference between the sample and control groups is due only to chance; $95 \% \mathrm{CI}, 95 \%$ confidence interval; TRG, target; REF, reference.

from the LNCaP cells exposed to RLN 2, where no increase was observed. Furthermore, the results of the densitometry analysis of MMP zymographic activities show that changes of gelatinase A were more pronounced than in gelatinase B in the 

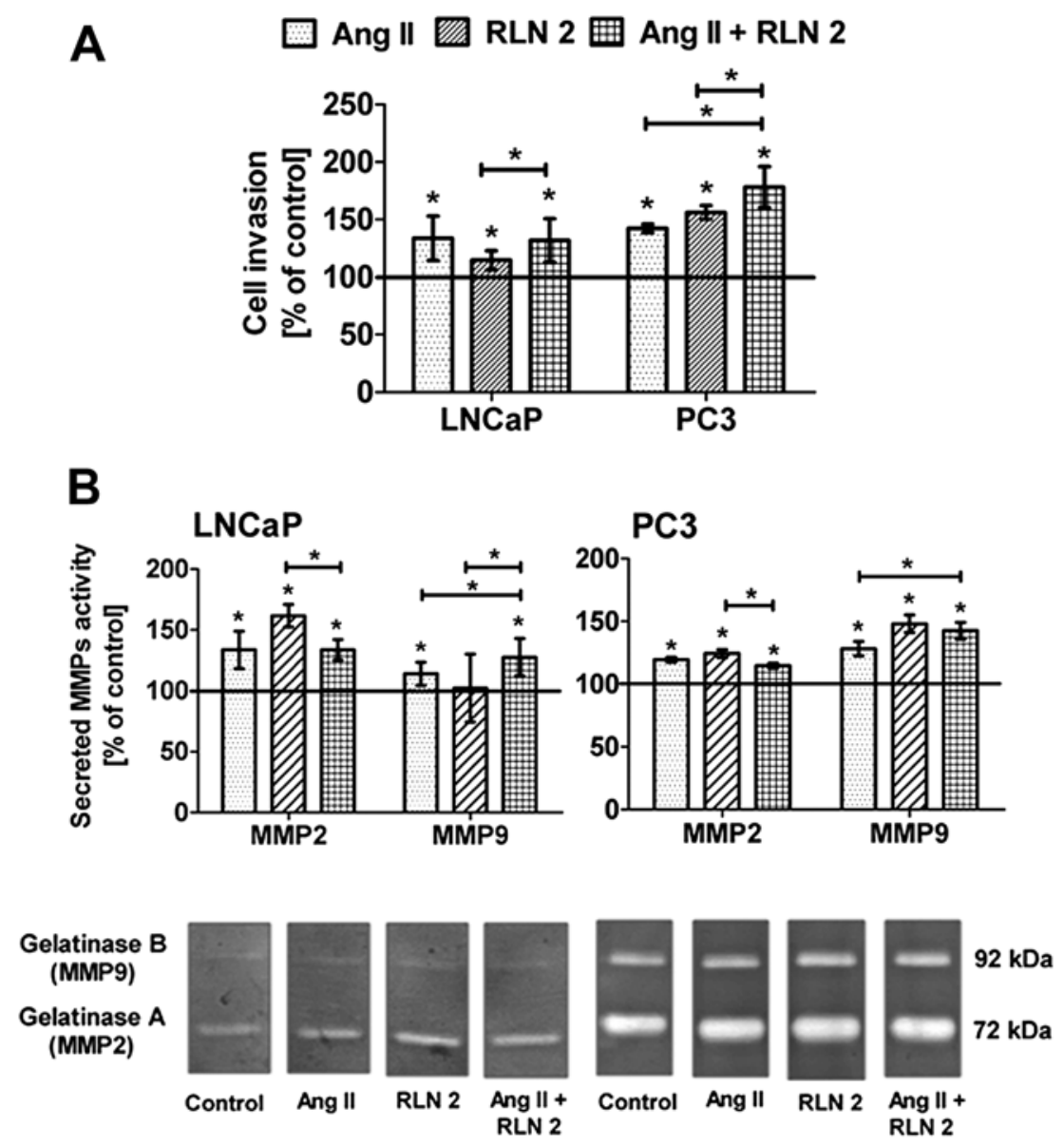

Figure 4. Invasion ability of prostate cancer cell lines after incubation with Ang II and/or RLN2. (A) The results in Transwell invasion chamber assays (48 h). (B) The change in the level of MMP-2 and MMP-9 secretion determined by the gelatin zymography assay. Error bars denote mean \pm SD whilst the asterisk shows significant differences compared to controls (mean $\pm \mathrm{SD}$; $\geq 8$; Tukey's test: ${ }^{*}<<0.05$ ).

PC3 cells, while in LNCaP cells, greater changes were noted for MMP-2.

Effects of Ang II and/or RLN2 on anchorage-independent cell growth. The ability to exhibit anchorage-independent cell growth was observed in both prostate cancer lines. As shown in Fig. 5, RLN2 increased the growth of both androgen-dependent and androgen-independent prostate cancer cells in soft agar. Furthermore, these results demonstrated that Ang II has no influence on the anchorage-independent growth of LNCaP. In the case of PC3 cells, Ang II was observed to have a poor stimulatory effect which was not statistically significant. Results for combination of Ang II and RLN2 oscillated within the control samples.

\section{Discussion}

It is common knowledge that local hormones such as angiotensin and relaxin regulate a wide range of prostatic functions. Nevertheless, detailed role of Ang II and RLN2 peptides in prostate physiology and pathology is still not clear. The present study examines the common effects of angiotensin II or relaxin 2 administration on various aspects of prostate cancer growth and progression. The weakly tumorigenic LNCaP prostate cancer cell line and the aggressively tumorigenic PC3 cell line were used as models of early

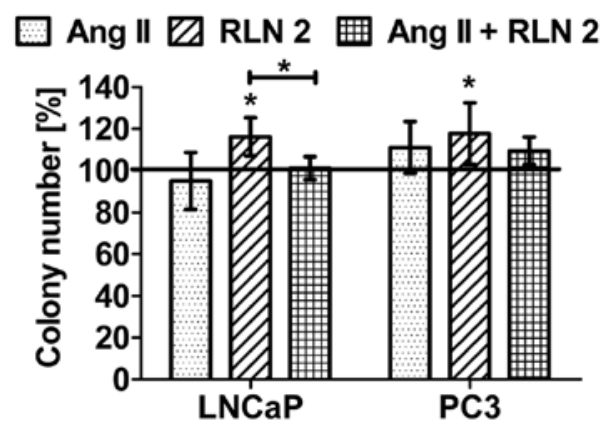

Figure 5. Soft agar growth for prostate cancer cells after incubation with Ang II and/or RLN2. Error bars denote mean \pm SD whilst the asterisk shows significant differences compared to controls (mean $\pm \mathrm{SD} ; \mathrm{n} \geq 4$; Tukey's test: " $\mathrm{p}<0.05)$.

stage androgen-dependent prostate cancer and late androgenindependent stage disease, respectively.

In this study, it was observed that relaxin 2 improved maintenance of cellular viability and proliferation of both the LNCaP and PC3 prostate cancer cell lines. These results confirm earlier studies showing that this peptide hormone promotes the division of prostate cancer cells (6). Experimental studies report that greater changes of cell proliferation take place in the high AR expression cells (LNCaP) than low AR 
expression cells (PC3). Liu et al (23) noted that $\mathrm{H} 2$ relaxin induces the transcriptional activity of AR and the growth of prostate cancer cells through increased expression of $\beta$-catenin. Furthermore PI3K/Akt, factors of the Wnt pathway, can facilitate $\mathrm{H} 2$-relaxin-mediated activation of the AR pathway (23). Vinall et al (24) report that the cAMP/PKA and $\mathrm{NF}-\mathrm{\kappa B}$ pathways play an important role in facilitating the $\mathrm{H} 2$ relaxin-mediated castration resistant growth of prostate cancer cells.

The findings of the present study reveal a significant increase in androgen receptor expression in $\mathrm{LNCaP}$ cells but an insignificant decrease in PC3. Some of the data generated in PC3 cells seem to contradict the conventional idea that the AR functions as a stimulator in prostate tumor growth and metastasis. For example Niu et al (25) noted that restoring AR in PC3 cells could suppress their ability to invade in vitro and in vivo. Whereas Lin et al (26) hypothesize that PC3 cells possess cellular machinery that turns the AR in PC3-AR cells into a growth suppressor. In another study, an equally interesting observation is that RLN2 is negatively regulated by androgens in prostate cancer (in vitro and in vivo) through the AR, implying that RLN2 levels increase in the both the absence of androgens and their ablation (27). It seems that this polypeptide hormone is involved in the mechanism of transformation from the androgen-dependent to androgenindependent state of prostate cancer cells.

Using a BrdUrd incorporation assay as an indicator of cell proliferation, it was noted that Ang II increased the DNA synthesis much more strongly in LNCaP cells than in PC3 cells. Our earlier studies found that Ang II significantly enhanced cell viability and proliferation in both prostate cancer cell lines $(21,28)$. Uemura et al $(29)$ found that AT1 receptor mRNA was strongly expressed in LNCaP cells and very poorly in $\mathrm{PC} 3$, which may explain the better response of the first line to angiotensin II-induced cell proliferation. Our observation seems compatible also with finding of Pawlikowski et al (30) presenting that expression of Ang II type 1 and 2 receptors in neoplastic epithelium of Gleason grate 2 is higher than in more advanced cancerous structures of Gleason grades 3-5. On the contrary, Chow et al (31) demonstrated that Ang II dose-dependently stimulated DNA synthesis in $\mathrm{LNCaP}$ but not PC3 cells suggesting that only $\mathrm{LNCaP}$ has the functional state of AT1.

However, the above observation is contradictory to our earlier findings, which identified the presence of AT1 receptor mRNA, and the expression of its protein in PC3 cells. The angiotensin II type 1 receptor antagonist candesartan revealed that Ang II has a stimulatory effect on metabolic activity and prostate cancer cell division in PC3 cells (21). This difference in the results may also be due to variables such as differences in type of antagonist, peptide concentration and time of incubation or differences in research techniques. The findings of the present study highlight some differences between the results of the MTT and Alamar blue assays: for example, the former showed a significant increase in PC3 cell viability after incubation with Ang II (48 h), whereas the latter did not. Both tests measure the metabolic activity of cells but in different ways. The first method measures the mitochondrial metabolic activity in the whole cells while the second assay indicates the total metabolic activity (mitochondrial and cytoplasmatic) in the entire cell culture. It is worth noting that while MTT can be reduced by NADPH, FADH, FMNH or NADH, Alamar blue can also be reduced by cytochromes $(32,33)$. Discrepancies between results from MTT and Alamar blue have also been reported by other workers in cytotoxicity studies (34).

Many molecules are known to regulate and modulate the cellular pathways related to cell division and survival, among which are survivin (BIRC5) and members of the BCL2 family. $B I R C 5$ is rarely expressed in most terminally differentiated normal tissues but is abundantly and ubiquitously expressed during fetal and embryonic development. Of note, survivin is up-regulated in almost all human malignant tumors and recently has been considered as a diagnostic and prognostic marker for human PCa $(35,36)$. An examination of clinical samples has established that the expression of survivin gradually rises from the low levels observed in normal prostate tissue, through low-grade primary carcinoma, to high-grade primary carcinoma, and is highest in lymph node metastases $(15,37)$. As expected, a higher level of BIRC5 expression was observed in aggressive androgen-independent prostate cancer cells (PC3) compared to the androgendependent, non-invasive prostate cancer cell line (LNCaP) (data not shown). Furthermore, both Ang II and RLN2 were found to stimulate survivin mRNA synthesis, mainly in the LNCaP cancer cells. Zhang et al (15) noted that survivin can mediate resistance to androgen ablation in prostate cancer via activation of the IGFR1/AKT pathway, suggesting that Ang II and RLN2 may play a role in the development of AIPC (androgen-independent prostate cancer) just by promoting the expression of BIRC5.

As the early stages of prostate cancer are typically asymptomatic and that the cells acquire motility, i.e. the ability to move to another location, this kind of cancer is very frequently fatal (38). Migration of cancer cells is critically regulated by physical adhesion of cells to each other and the extracellular matrix (ECM). The present study examines the ability of prostate cancer cells to adhere to the major structural elements of the ECM, such as type I and IV collagen, laminin and fibronectin. Our results are similar to those of Moro et al (39) indicating that carcinoma cells adhere to different degrees to various components of the basement membrane. As shown in the present study, extent of prostate cell adhesion was dependent firstly on the type of prostate cell, on the kind of protein matrix and finally on the duration of Ang II and RLN2 incubation. Nevertheless, after 48-h incubation, increased adhesion of both $\mathrm{LNCaP}$ and PC3 prostate cancer cells was observed in all tested combinations. Feng et al (6) evaluated the effect of relaxin 2 on adhesion of LNCaP and PC3 cells, but only to type I collagen. They observed that pre-incubation with different concentrations of relaxin $2(0-300 \mathrm{ng} / \mathrm{ml})$ resulted in a dose-dependent increase in prostate cancer cell adhesion (6). The modulation of cell adhesion to ECM by angiotensin II has also been observed by other researchers (40).

Prostate cancer tends to spread to either lymph nodes or bones (38). During this metastasis, tumor cells must pass through structural barriers such as basement membranes. The matrix metalloproteinases are believed to be the most important physiological mediators of ECM degradation. Increased expression of MMPs has been observed in various cancers 
and many reports indicate their potential prognostic value in patients with prostate cancer (18). The gelatin zymography used in the present study revealed that both prostate cancer cell lines secreted MMP-2 and MMP-9 into the culture medium. In controls, it was observed that PC3 cells secrete many times more gelatinase A and B than LNCaP cells, which certainly affects the differences in invasiveness of both cell lines. Our findings add to an increasing body of evidence suggesting that both Ang II and RLN2 play an important role in the normal and pathological remodeling of ECM in several reproductive tract tissues (1-3). The results of the present study demonstrate the levels of gelatinases clearly grew after exposure to Ang II and RLN2, which is supported by the results of the Transwell invasion assay. These findings confirm that both peptide hormones can promote a more aggressive and invasive phenotype in prostate cancer via upregulation of MMPs. Feng et al (6) indicated a significant increase in invasiveness of relaxin-treated $\mathrm{LNCaP}$ and PC-3 cells in the Matrigel invasion assay.

The cancer cells travel to new organs via the lymph or blood stream. Therefore, the next critical step in the multistage process of metastasis formation is the ability to survive and grow in the absence of anchorage to the extracellular matrix and their neighboring cells (14). Our results clearly show that only relaxin 2 can induce a higher anchorageindependent growth and non-adherent spheroid formation of both LNCaP and PC3 cells in a soft agar medium. The angiotensin II effect, in this case, does not play a significant role, because the number of colony formation remains almost unaltered.

The present study is the first to consider the impact of Ang II and RLN2, alone and in combination, on prostate cancer cells. The obtained results confirm their influence on prostate cancer cells, in terms of cell viability and proliferation, cell adhesion and invasion. Nevertheless, the stimulatory potency of either Ang II or RLN2 when used alone was not found to increase synergistically/additively when both peptides were used in combination; the effects of both hormones in combination were most frequently intermediate between the two individual values or sometimes lower than both. The obtained results suggest that the investigated RAS and relaxin family peptide system may have impact on cell growth/division or spread at least in part via overlapping signal transduction pathways. Ang II and RLN2 may well play an important role in increasing the aggressiveness of prostate tumors by the upregulation of survivin expression and gelatinase secretion. Furthermore, it can be speculated that Ang II and RLN2 are involved in the transition from the androgen-dependent to the androgen-independent phenotype via modulation of the expression of androgen receptors. However, further studies are necessary to confirm this hypothesis and to elucidate the mechanisms involved.

\section{Acknowledgements}

This work was financially supported by the National Science Center, research grant no. NN403 208139.

\section{References}

1. Silvertown JD, Summerlee AJ and Klonisch T: Relaxin-like peptides in cancer. Int J Cancer 107: 513-519, 2003.
2. Domińska K and Lachowicz-Ochedalska A: The involvement of the renin-angiotensin system (RAS) in cancerogenesis. Postepy Biochem 54: 294-300, 2008 (In Polish).

3. Domińska K: Relaxin 2 - a pregnancy hormone involved in the process of carcinogenesis. Ginekol Pol 84: 126-130, 2013 (In Polish).

4. Dinh DT, Frauman AG, Somers GR, Ohishi M, Zhou J, Casley DJ, Johnston CI and Fabiani ME: Evidence for activation of the renin-angiotensin system in the human prostate: Increased angiotensin II and reduced AT(1) receptor expression in benign prostatic hyperplasia. J Pathol 196: 213-219, 2002.

5. Louis SN, Wang L, Chow L, Rezmann LA, Imamura K, MacGregor DP, Casely D, Catt KJ, Frauman AG and Louis WJ: Appearance of angiotensin II expression in non-basal epithelial cells is an early feature of malignant change in human prostate. Cancer Detect Prev 31: 391-395, 2007.

6. Feng S, Agoulnik IU, Bogatcheva NV, Kamat AA, Kwabi-Addo B Li R, Ayala G, Ittmann MM and Agoulnik AI: Relaxin promotes prostate cancer progression. Clin Cancer Res 13: 1695-1702, 2007.

7. Feng S, Agoulnik IU, Li Z, Han HD, Lopez-Berestein G, Sood A, Ittmann MM and Agoulnik AI: Relaxin/RXFP1 signaling in prostate cancer progression. Ann NY Acad Sci 1160: 379-380, 2009.

8. Lamp O, Honscha KU, Schweizer S, Heckmann A, Blaschzik S and Einspanier A: The metastatic potential of canine mammary tumours can be assessed by mRNA expression analysis of connective tissue modulators. Vet Comp Oncol 11: 70-85, 2013.

9. Chow BS, Kocan M, Bosnyak S, Sarwar M, Wigg B, Jones ES, Widdop RE, Summers RJ, Bathgate RA, Hewitson TD, et al: Relaxin requires the angiotensin II type 2 receptor to abrogate renal interstitial fibrosis. Kidney Int 86: 75-85, 2014.

10. Sasser JM, Molnar M and Baylis C: Relaxin ameliorates hypertension and increases nitric oxide metabolite excretion in angiotensin II but not $\mathrm{N}(\omega)$-nitro-L-arginine methyl ester hypertensive rats. Hypertension 58: 197-204, 2011.

11. Ferreira VM, Gomes TS, Reis LA, Ferreira AT, Razvickas CV, Schor N and Boim MA: Receptor-induced dilatation in the systemic and intrarenal adaptation to pregnancy in rats. PLoS One 4: e4845, 2009.

12. Geddes BJ, Parry LJ and Summerlee AJ: Brain angiotensin-II partially mediates the effects of relaxin on vasopressin and oxytocin release in anesthetized rats. Endocrinology 134: 1188-1192, 1994.

13. Amamoo A and Wilson BC: Relaxin inhibits central angiotensin II expression in killifish: A central osmoregulatory role for relaxin and angiotensin II in the killifish Fundulus heteroclitus. Ann NY Acad Sci 1041: 229-232, 2005.

14. Friedl $\mathrm{P}$ and Wolf $\mathrm{K}$ : Tumour-cell invasion and migration: Diversity and escape mechanisms. Nat Rev Cancer 3: 362-374, 2003.

15. Zhang M, Latham DE, Delaney MA and Chakravarti A: Survivin mediates resistance to antiandrogen therapy in prostate cancer. Oncogene 24: 2474-2482, 2005.

16. Duffy MJ, O'Donovan N, Brennan DJ, Gallagher WM and Ryan BM: Survivin: A promising tumor biomarker. Cancer Lett 249: 49-60, 2007.

17. Lin Y, Fukuchi J, Hiipakka RA, Kokontis JM and Xiang J: Up-regulation of $\mathrm{Bcl}-2$ is required for the progression of prostate cancer cells from an androgen-dependent to an androgenindependent growth stage. Cell Res 17: 531-536, 2007.

18. Hadler-Olsen E, Winberg JO and Uhlin-Hansen L: Matrix metalloproteinases in cancer: Their value as diagnostic and prognostic markers and therapeutic targets. Tumour Biol 34: 2041-2051, 2013.

19. Alimirah F, Chen J, Basrawala Z, Xin H and Choubey D: DU-145 and PC-3 human prostate cancer cell lines express androgen receptor: Implications for the androgen receptor functions and regulation. FEBS Lett 580: 2294-2300, 2006.

20. Piastowska-Ciesielska AW, Gajewska M, Wagner W, Dominska K and Ochedalski T: Modulatory effect of selenium on cell-cycle regulatory genes in the prostate adenocarcinoma cell line. J Appl Biomed 12: 87-95, 2014.

21. Piastowska-Ciesielska AW, Kozłowski M, Wagner W, Domińska K and Ochędalski T: Effect of an angiotensin II type 1 receptor blocker on caveolin-1 expression in prostate cancer cells. Arch Med Sci 9: 739-744, 2013

22. Pluciennik E, Krol M, Nowakowska M, Kusinska R, Potemski P, Kordek R and Bednarek AK: Breast cancer relapse prediction based on multi-gene RT-PCR algorithm. Med Sci Monit 16: CR132-CR136, 2010. 
23. Liu S, Vinall RL, Tepper C, Shi XB, Xue LR, Ma AH, Wang LY, Fitzgerald LD, Wu Z, Gandour-Edwards R, et al: Inappropriate activation of androgen receptor by relaxin via beta-catenin pathway. Oncogene 27: 499-505, 2008.

24. Vinall RL, Mahaffey CM, Davis RR, Luo Z, Gandour-Edwards R, Ghosh PM, Tepper CG and de Vere White RW: Dual blockade of PKA and NF- $\kappa$ B inhibits $\mathrm{H} 2$ relaxin-mediated castrate-resistan growth of prostate cancer sublines and induces apoptosis. Horm Cancer 2: 224-238, 2011.

25. Niu Y, Altuwaijri S, Lai KP, Wu CT, Ricke WA, Messing EM, Yao J, Yeh S and Chang C: Androgen receptor is a tumor suppressor and proliferator in prostate cancer. Proc Natl Acad Sci USA 105: 12182-12187, 2008.

26. Lin B, Wang J, Hong X, Yan X, Hwang D, Cho JH, Yi D, Utleg AG, Fang X, Schones DE, et al: Integrated expression profiling and ChIP-seq analyses of the growth inhibition response program of the androgen receptor. PLoS One 4: e6589, 2009.

27. Thompson VC, Morris TG, Cochrane DR, Cavanagh J, Wafa LA, Hamilton T, Wang S, Fazli L, Gleave ME and Nelson CC: Relaxin becomes upregulated during prostate cancer progression to androgen independence and is negatively regulated by androgens. Prostate 66: 1698-1709, 2006.

28. Domińska K, Piastowska-Ciesielska AW, LachowiczOchędalska A and Ochędalski T: Similarities and differences between effects of angiotensin III and angiotensin II on human prostate cancer cell migration and proliferation. Peptides 37 : 200-206, 2012.

29. Uemura H, Ishiguro H, Nakaigawa N, Nagashima Y, Miyoshi $Y$, Fujinami K, Sakaguchi A and Kubota Y: Angiotensin II receptor blocker shows antiproliferative activity in prostate cancer cells: A possibility of tyrosine kinase inhibitor of growth factor. Mol Cancer Ther 2: 1139-1147, 2003.

30. Pawlikowski M, Minias R, Sosnowski M and Zielinski KW: Immunohistochemical detection of angiotensin AT1 and AT2 receptors in prosate cancer, Central Eur. J Urol 64: 252-255, 2011.

31. Chow L, Rezmann L, Imamura K, Wang L, Catt K, Tikellis C, Louis WJ, Frauman AG and Louis SNS: Functional angiotensin II type 2 receptors inhibit growth factor signaling in $\mathrm{LNCaP}$ and PC3 prostate cancer cell lines. Prostate 68: 651-660, 2008.
32. Rampersad SN: Multiple applications of Alamar Blue as an indicator of metabolic function and cellular health in cell viability bioassays. Sensors (Basel) 12: 12347-12360, 2012.

33. Niles AL, Moravec RA and Riss TL: Update on in vitro cytotoxicity assays for drug development. Expert Opin Drug Discov 3: 655-669, 2008.

34. Hamid R, Rotshteyn Y, Rabadi L, Parikh R and Bullock P: Comparison of alamar blue and MTT assays for high through-put screening. Toxicol In Vitro 18: 703-710, 2004.

35. Khan S, Jutzy JM, Valenzuela MM, Turay D, Aspe JR, Ashok A, Mirshahidi S, Mercola D, Lilly MB and Wall NR: Plasma-derived exosomal survivin, a plausible biomarker for early detection of prostate cancer. PLoS One 7: e46737, 2012.

36. Arbab IA, Looi CY, Abdul AB, Cheah FK, Wong WF, Sukari MA, Abdullah R, Mohan S, Syam S, Arya A, et al: Dentatin Induces apoptosis in prostate cancer cells via Bcl-2, $\mathrm{Bcl}-\mathrm{xL}$, survivin downregulation, caspase- $9,-3 / 7$ activation, and NF- $\kappa$ B inhibition. Evid Based Complement Alternat Med 2012: 856029,2012

37. Shariat SF, Lotan Y, Saboorian H, Khoddami SM, Roehrborn CG, Slawin KM and Ashfaq R: Survivin expression is associated with features of biologically aggressive prostate carcinoma. Cancer 100: 751-757, 2004

38. Arya M, Bott SR, Shergill IS, Ahmed HU, Williamson M and Patel HR: The metastatic cascade in prostate cancer. Surg Oncol 15: 117-128, 2006

39. Moro L, Arbini AA, Marra E and Greco M: Up-regulation of Skp2 after prostate cancer cell adhesion to basement membranes results in BRCA2 degradation and cell proliferation. J Biol Chem 281: 22100-22107, 2006.

40. Rodrigues-Ferreira S, Abdelkarim M, Dillenburg-Pilla P, Luissint AC, di-Tommaso A, Deshayes F, Pontes CL, Molina A, Cagnard N, Letourneur F, et al: Angiotensin II facilitates breast cancer cell migration and metastasis. PLoS One 7: e35667, 2012. 